\title{
Building a relational contracting culture and integrated teams
}

\author{
M. Motiar Rahman, Mohan M. Kumaraswamy, and Florence Yean Yng Ling
}

\begin{abstract}
Targeting integration in construction, this study compares the suitability of various factors and strategies to provide suitable contractual and noncontractual incentives for building a relational contracting (RC) culture and fostering effective teamwork. Results from statistical analyses of 96 questionnaire responses from Singapore contractors, consultants, and clients are presented. Despite obvious differences in perceptions among different groups of respondents on the relative usefulness of individual factors, it was observed that trust should broadly be at the core of RC and teambuilding. Although some factors appear to be more important than others, the overall results indicate that Singaporean industry participants prefer to target integration in construction through $(i)$ trust-based contractual and operational arrangements and (ii) extended use of relational qualities in team selection for postcontract partnering-type RC arrangements between clients and contractors. The results also suggest the need for an interrelated and consolidated approach, both for propagating RC and for building integrated project teams. Like many other countries, the results indicate the readiness of Singaporean industry participants to incorporate RC and team-building techniques in a move towards improved performance and value for money. The results may be applicable to other countries or contracting regimes, especially where the practice of RC is at an early stage. Outcomes of this study are expected to benefit both industry practitioners and researchers in exploring, designing, and implementing suitable contractual and noncontractual incentives.
\end{abstract}

Key words: construction, culture, integration, relational contracting, Singapore, team-building.

Résumé : La présente étude cible l'intégration en construction en comparant l'adéuation de divers facteurs et stratégies pour fournir des incitatifs contractuels et non contractuels adéquats afin de bâtir une culture de passation de contrats relationnels (« $\mathrm{RC} »)$ et encourager un travail en équipe efficace. Les résultats d'analyse statistique de 96 réponses d'entrepreneurs, de consultants et de clients de Singapour à un questionnaire sont présentés. Malgré les différences marquées dans la perception des divers groupes de répondants quant à l'utilité relative des facteurs individuels, il a été remarqué que la confiance est à la base même de la passation de contrats relationnels et de l'établissement d'un esprit d'équipe. Bien que certains facteurs semblent avoir plus d'importance que d'autres, les résultats généraux indiquent que les industriels singapouriens préfèrent cibler l'intégration dans la construction par $(i)$ des accords opérationnels et contractuels basés sur la confiance et (ii) l'utilisation répandue de qualités relationnelles lors de l'établissement des équipes après la fin du contrat pour des ententes de passation de contrats relationnels de type partenariat entre les clients et les entrepreneurs. Les résultats suggèrent aussi le besoin d'utiliser une approche interdépendante et consolidée pour encourager la passation de contrats relationnels et développer des équipes de travail intégrées. Comme dans plusieurs autres pays, les résultats indiquent que les industriels singapouriens sont prêts à intégrer la passation de contrats relationnels et les techniques de développement du travail en équipes afin d'améliorer le rendement et le retour sur l'investissement. Les résultats peuvent s'appliquer à d'autres pays ou régimes de passation de contrats, plus particulièrement lorsque la pratique des passations de contrats relationnels est à un stade précoce. Les résultats de cette étude devraient encourager les intervenants et les chercheurs de l'industrie à explorer, à concevoir et à implanter des incitatifs contractuels et non contractuels adéquats.

Mots-clés : construction, culture, intégration, passation de contrats relationnels, Singapour, établissement d'un esprit d'équipe.

[Traduit par la Rédaction]

Received 12 September 2005. Revision accepted 9 August 2006. Published on the NRC Research Press Web site at http://cjce.nrc.ca on 8 March 2007.

M.M. Rahman ${ }^{1,2}$ and M.M. Kumaraswamy. Department of Civil Engineering, The University of Hong Kong, Pokfulam, Hong Kong.

F.Y.Y. Ling. Department of Building, National University of Singapore, Singapore.

Written discussion of this article is welcomed and will be received by the Editor until 31 May 2007.

${ }^{1}$ Corresponding author (e-mail: mrahman@glam.ac.uk).

${ }^{2}$ Present address: School of Technology, University of Glamorgan, Pontypridd CF37 1DL, UK. 


\section{Introduction}

Many high-level industry reports have pointed out the importance of relationships and team-building among project participants for improved performance and integration in construction (Egan 1998; Construction 21 1999; CIRC 2001). Many traditionally oriented contracting approaches may not support such integration and team-building, however. Essentially, a change in contracting approach is necessary, both in contractual and noncontractual terms. For example, a change in contractual terms may include clear and equitable risk allocation, whereas a change in noncontractual terms may include a change in the attitude for such equitable risk allocation. The application of relational contracting (RC) principles is one of the approaches that triggers such changes. Relational contracting considers contracts to be relationships among the parties, in the process of projecting exchange into the future, and allows mutual future planning (Macneil 1974). This is useful in the sense that construction contracts are complex and require future adjustments, in particular to address unforeseen events, where mutual understanding and relationships among contracting parties play an important role. Previous research has identified, from among many others, that RC principles offer contractual flexibility, supply essential elements of team-building, lubricate transactional barriers, smoothen ongoing contractual relationships, and suggest rationalized selection criteria in building effective project teams (Rahman and Kumaraswamy 2004a).

Relational contracting principles underpin various approaches such as partnering, alliancing, joint venturing, longterm contracting, and other collaborative working arrangements and improved risk allocation/sharing mechanisms (Rahman and Kumaraswamy 2002a). Moreover, the potential for implementing RC and RC-based team-building protocols in construction, for example joint risk management, has been verified (Rahman and Kumaraswamy 2004b). Despite such suitability and potential improvements towards integration, construction industries are apparently hesitant in adopting RC, probably because of the perceived uncertainties, e.g., in possibly unclear responsibility allocations. Zaghloul and Hartman (2003) observed in Canada that contractors add a staggering 8\%-20\% extra costs to their bids to cover their perceptions of high risk-uncertainty related to the five most common exculpatory clauses in current contracts. It was therefore felt essential to incorporate $\mathrm{RC}$ principles in contract documents, through "less but more effective" regulations, to promote a relational culture in construction that will also ensure value for money (PSIB 2004). A general guideline appears to be useful in propagating the practice of $\mathrm{RC}$ and team-building in multiparticipant construction projects, to provide any contractual and noncontractual incentives, and for targeting relational integration in various professional, organizational, operational, and regional/national cultures.

Based on the aforementioned and to provide appropriate $\mathrm{RC}$-based contractual and noncontractual incentives in construction, a study was launched from Hong Kong. The target was to identify key factors (i) facilitating RC, (ii) deterring $\mathrm{RC}$, (iii) facilitating the building of integrated project teams for more effective RC, and (iv) deterring the building of integrated project teams for more effective RC. The survey was conducted in five different countries. This paper presents the perceptions of 96 respondents from Singapore. Hence, the main purpose of this paper is to identify and present various $\mathrm{RC}$-based contractual and noncontractual incentives in Singapore, in terms of RC and integrated team-working. This country was one of those specifically chosen for the study, since the Singapore construction industry has (like some others) recognized problems of cost overruns, program delays, and poor productivity (Construction 21 1999). Despite the recommendations for a more integrated procurement approach, the industry has not yet shifted much from the traditional approach. The general view is that the design-bid-build approach provides a measure of protection to less informed developers and other clients who lack faith in the professionalism of their contractors. It was therefore felt that any RCbased initiative in Singapore has to be contractual or under some type of regulatory framework.

\section{Methodological approach}

\section{Questionnaire survey}

The questionnaire was developed in Hong Kong on the basis of a recent study on "revitalised procurement strategies" that included $(i)$ an extensive literature review of both "contract theory," in the context of mainstream "socioeconomic" (i.e., transaction cost economics) and "sociolegal" (i.e., RC) approaches, and practice of various kinds of contracting approaches in construction; and (ii) Hong Kong based surveys on risk allocation and collaborative working arrangements, including assessing the potential for implementing RC and various RC-based team-building protocols, such as joint risk management (Rahman 2003; Rahman and Kumaraswamy 2002b, 2004a, 2004b, 2005a, 2005b). The present study specifically targets the building of a culture of $\mathrm{RC}$ and team-building in construction, through identifying various RC-based contractual and noncontractual incentives. Accordingly, the individual factors used in the questionnaire were consolidated and refined from the aforementioned studies and tuned to fit the specific purposes of the present study.

Section 1 of the questionnaire requested general information about the respondents for survey sample composition. The subsequent four sections of the questionnaire requested the respondents to express their perceived importance on a scale from 0 to 6 (varying from lowest to highest) on four categories of factors: 24 factors facilitating RC (category one), 28 factors deterring RC (category two), 28 factors facilitating the building of integrated project teams (category three), and 31 factors deterring the building of integrated project teams (category four). These factors are listed in Appendix A. The questionnaire also included introductory notes, explaining the purposes of different sections, and the questionnaire "as a whole."

A total of 400 questionnaires were distributed to randomly selected groups of contractors, consultants, and clients. Stamped and self-addressed envelopes were provided for the convenience of the potential respondents. The number of questionnaires distributed, responses received, and experiences of the respondents are shown in Table 1. A total of 96 responses were received, giving an overall response rate of $24 \%$, and the respondents have an average total experience of 12.7 years in construction and 3.0 years in RC approaches, respectively. It appears that the concept of $\mathrm{RC}$ - 
Table 1. Questionnaire distribution and respondent profile.

\begin{tabular}{|c|c|c|c|c|}
\hline & Contractor & Consultant & Client & Total \\
\hline No. of questionnaires distributed & 200 & 100 & 100 & 400 \\
\hline No. of responses received $(\%)$ & $60(30)$ & $21(21)$ & $15(15)$ & $96(24)$ \\
\hline \multicolumn{5}{|l|}{ Total construction experience } \\
\hline No. of responses & 58 & 14 & 8 & 80 \\
\hline Average (years) & 12.2 & 17.3 & 9.0 & 12.7 \\
\hline Range (years) & $2-30$ & $3-35$ & $2-24$ & $2-35$ \\
\hline \multicolumn{5}{|l|}{ Total experience in $\mathrm{RC}$} \\
\hline No. of responses & 38 & 6 & 5 & 49 \\
\hline Average (years) & 2.3 & 6.5 & 3.4 & 3.0 \\
\hline Range (years) & $0-23$ & $0-20$ & $0-10$ & $0-23$ \\
\hline \multicolumn{5}{|l|}{ Experience in RC (no. of projects) } \\
\hline No. of responses & 38 & 7 & 5 & 50 \\
\hline Average & $1.76(\sim 2)$ & $15.57(\sim 16)$ & $4.60(\sim 5)$ & $3.98(\sim 4)$ \\
\hline Range & $0-16$ & $0-100$ & $1-10$ & $0-100$ \\
\hline
\end{tabular}

type integrated approaches is relatively new in Singapore in comparison to other countries such as the UK and USA. On the other hand, the concept of such integrated approaches in Canada is not so "new," since even consultants were seen to encourage partnering with clients in the mid-1990s (CCE 1994, 1995).

\section{Data analysis}

Data were analyzed using the software SPSS (Statistical Package for the Social Sciences, version 12.0; SPSS Inc. 2003). The mean scores of individual factors by different groups of respondents were ranked and compared. Statistical $t$ tests of the mean with a significance level of 0.05 were undertaken to establish whether each factor is significantly important for the whole sample (number of responses $n=96$ ) and the contractors $(n=60)$, consultants $(n=21)$, and clients $(n=15)$ groups. The null hypothesis $\left(H_{0}\right)$ was that the factor identified was not important. If $p<0.05$, the decision was to reject $H_{0}$ and accept $H_{1}$. It was then concluded that the population consider that the specific factor is significantly important. To examine whether different groups of respondents had different perceptions of the relative importance of various individual factors, analysis of variance (ANOVA) was carried out at the $95 \%$ confidence interval (i) between the contractors and consultants groups, consultants and clients groups, and contractors and clients groups; and (ii) for the three groups of respondents together. The null hypothesis $\left(H_{0}\right)$ was that the different groups of respondents have similar perceptions of different factors. The decision was to accept $H_{1}$ if $p<0.05$; otherwise, $H_{0}$ was accepted. To accept $H_{1}$ for a specific factor is to say that respondents from different groups had divergent perceptions of that factor. These are shown in Table 2 for factors facilitating $\mathrm{RC}$, where different factors have been arranged according to their rank in the total sample (i.e., $n=96$ ).

Lastly, factor analysis was carried out to narrow down the long list of factors to a smaller number of representative broad factors or components (see Table 3 for the factors facilitating RC). For the purpose of this exercise, the principal component method of extraction was applied, coupled with varimax with Kaiser normalization method of rotation. Eigenvalues for the extracted components of $\geq 1.0$ were con- sidered, and factor loadings of $<0.30$ have been suppressed. This last cutoff decision of presenting factor loadings of $\geq 0.30$ was taken to show the contributions from the significant factor a13: mutually agreed issue resolution mechanisms (see Table 2 in which the significance level obtained from the $t$ test is 0.000 ; also see Table 3 in which the highest contribution is 0.34 ). In case of contributions to more than one component, factors with the highest factor loadings were considered as "primary" contributors, and other factors were considered as "secondary" contributors. In the interests of brevity, Tables 4-6 summarize the corresponding results of factor analysis only, along with the means and ranks of different factors for the total sample of the other three categories.

\section{Results}

\section{Factors facilitating relational contracting}

Table 2 shows the perceptions of respondents on 24 factors for facilitating RC. It is found that "mutual trust" (a07, score 5.36) is the most important factor for facilitating RC. In this respect, mutual trust was defined as a social relation characterized by contracting parties being both trusting and trustworthy: a party is trustworthy if it successfully resists opportunism and trusting if it believes the other party is trustworthy (Lyons and Mehta 1997). This is followed by "open communication" (a06) and "teamworking and can do spirit" (a10). "Effective coordination" (a08) and "combined responsibility" (a09) jointly hold rank 4.

"Top management support of all contracting parties" (a04, rank 7) is more important than "enlightened and enthusiastic client" (a01, rank 17). This is because top management formulates company strategies and directs business activities. Their full support and commitment are critical in initiating, leading, and maintaining the spirit to cooperate (Chan et al. 2004; Cheng and Li 2004). On the other hand, clients initiate the projects, control the project organization, prepare the contract conditions, and select other project team members. Therefore, clients should lead and lay the basis for any cooperation and motivate others (Rahman and Kumaraswamy $2004 b$ ). Efforts and support from such enthusiastic and enlightened clients by themselves, however, cannot harvest ex- 


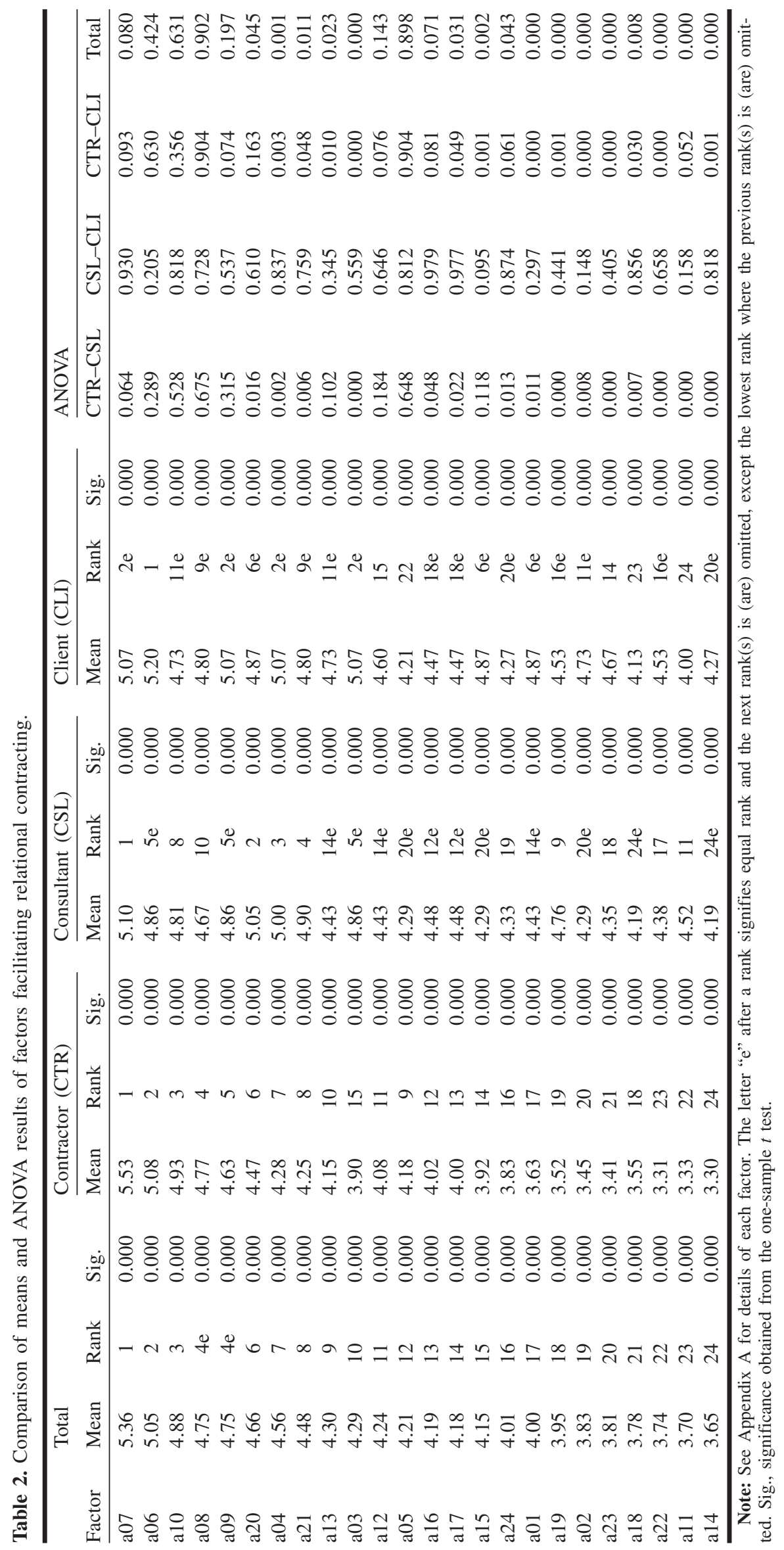


Table 3. Factor analysis outcomes of factors facilitating relational contracting.

\begin{tabular}{|c|c|c|c|c|c|}
\hline \multirow[b]{2}{*}{ Factor } & \multicolumn{5}{|c|}{ Component } \\
\hline & 1 & 2 & 3 & 4 & 5 \\
\hline $\mathrm{a} 01$ & 0.84 & & & & \\
\hline $\mathrm{a} 03$ & 0.83 & & & & \\
\hline $\mathrm{a} 04$ & 0.78 & & & & \\
\hline $\mathrm{a} 02$ & 0.75 & & & & \\
\hline a19 & 0.74 & & & & \\
\hline a18 & 0.60 & & & & \\
\hline a23 & 0.59 & 0.59 & & & \\
\hline a14 & 0.55 & & 0.55 & & \\
\hline a09 & 0.51 & & & 0.33 & 0.43 \\
\hline a21 & & 0.78 & & & \\
\hline a20 & & 0.70 & & 0.32 & \\
\hline a22 & 0.45 & 0.68 & & & \\
\hline a24 & & 0.63 & 0.31 & & \\
\hline a17 & 0.30 & & 0.80 & & \\
\hline a16 & & & 0.75 & & \\
\hline a15 & 0.43 & & 0.67 & & \\
\hline a11 & 0.44 & & 0.49 & & \\
\hline a13 & 0.33 & & 0.34 & & \\
\hline $\mathrm{a} 07$ & & 0.37 & & 0.79 & \\
\hline a10 & & & & 0.71 & \\
\hline $\mathrm{a} 06$ & & & & 0.69 & 0.37 \\
\hline $\mathrm{a} 08$ & 0.30 & & 0.31 & 0.60 & 0.39 \\
\hline $\mathrm{a} 05$ & & & & & 0.78 \\
\hline a12 & 0.40 & & & & 0.72 \\
\hline Eigenvalue & 5.65 & 3.16 & 3.07 & 2.57 & 2.04 \\
\hline$\%$ of variance & 23.55 & 13.18 & 12.77 & 10.73 & 8.51 \\
\hline Cumulative $\%$ & 23.55 & 36.72 & 49.50 & 60.22 & 68.73 \\
\hline
\end{tabular}

Note: See Appendix A for details of each factor. Rotation converged in seven iterations. Kaiser-Meyer-Olkin measure of sampling adequacy was 0.872. Bartlett's test of sphericity: approximate $\chi^{2}=1442$, degrees of freedom $\mathrm{df}=276$, probability $p<0.000$.

pected benefits, since unwilling participation of any party is not productive for RC approaches (Mohr and Spekman 1994).

Alignment of different "objectives" (a15-a17, ranks 13$15)$ is more important than "enlightened" (a01, rank 17) and "knowledgeable" client (a02, rank 19). Relative importance of the factors "flexible/adjustable contracts to address uncertainties" (a22, rank 22) and "long-term commitment to each other" (a11, rank 23) seem to explain the tendency towards project-based and structured RC approaches, such as postcontract partnering."Mutually agreed performance appraisal mechanisms" (a14) is the least important factor, however, with a score of 3.65 , which is more than the average of the measurement scale (of 0-6), implying a general importance of all 24 factors. This is confirmed by the one-sample $t$ test: all the factors are significant for facilitating $\mathrm{RC}$, both in the total sample and by different groups of respondents.

The ANOVA results show that clients and consultants have similar perceptions of all 24 factors, although the ranks of different factors are different. On the other hand, the groupings of contractors and consultants and contractors and clients have similar perception only of eight and 11 factors, respectively, although the ranks of a few factors are either the same or similar. Further examination of the results reveals that the scores of the highest ranked factors in the contractors, consultants, and clients groups are 5.53, 5.10, and 5.20, respectively; and those for the lowest ranked factors are $3.30,4.19$, and 4.00 , respectively. These led to scores of 5.36 and 3.65 for the highest and lowest ranked factors, respectively, in the total sample. On the whole, three groups of respondents have similar perceptions of only eight factors.

Table 3 summarizes the outcomes from factor analysis for factors facilitating RC. Five components emerged from this exercise, and together they explained over $68 \%$ of the total variation. The percentages of variations explained by the five components are over $23 \%, 13 \%, 12 \%, 10 \%$, and $8 \%$, respectively. All the components are seen to feed from the factors that contribute to more than one component; as such, 14 (out of 24 , or $58 \%$ ) factors are seen to contribute to more than one component, and even up to four components. For example, factor a08 contributes to components $1,3,4$, and 5, with corresponding factor loadings of $0.30,0.31,0.60$, and 0.39 , respectively. Several factors are seen to contribute either equally or almost equally to more than one component; for example, the factor "encouraging and motivating riskreward plans" (a23) is seen to contribute to components 1 and 2 with an equal factor loading of 0.59 . The other two such factors are "mutually agreed performance appraisal mechanisms" (a14) and "mutually agreed issue-resolution mechanisms" (a13). Thus, all the components are highly interrelated with primary and secondary contributions of the factors, although nomenclature of different components (see Table 3; Appendix A) is based on their primary contributing factors only.

Component 1 is seen to feed from primary contributions of nine factors and secondary contributions of seven factors. This component shares more than one third of the total explained variation, implying that "client and top management support" is the prime requirement for facilitating RC. This observation is consistent with previous findings from Canada (e.g., Jergeas and Revay 1999) and elsewhere (e.g., Larson 1995; Black et al. 2000; Cheng and Li 2002). This component explains that "top management support" (a03, a04) from all contracting parties and enlightened and knowledgeable cliental behaviour ( $\mathrm{a} 01$, a02) help formulate better "risk-reward plans" (a23) and "mutually agreed performance appraisal mechanisms" (a14). Such arrangements also include combined responsibility (a09), which promotes "positive attitude towards continuous improvement" (a19) and encourages "learning climate/environment in project team organization" (a18).

Component 2 (appropriate contractual incentives) includes "clearly defined" (a20) and "equitable" (a21) risk allocation/ sharing arrangements among "all key parties" (a24) under "flexible contracts" (a22) to effectively manage construction risks, including any residual and unforeseen risks (Hartman et al. 1997; Jergeas and Revay 1999; Rahman and Kumaraswamy 2002b). "Alignment of team objectives" (component 3) covers alignment of mutual "project and commercial objectives" (a15, a16, a17) with mutual "long-term commitment" (a11) and "issue-resolution mechanisms" (a13). The literature suggests that dedication to common goals and an understanding of each other's individual expectations and values are two key aspects of partnering-type RC approaches (Baker 1990; Larson 1995). 
Table 4. Importance and factor analysis outcomes of factors deterring relational contracting.

\begin{tabular}{|c|c|c|c|c|c|c|c|c|}
\hline \multirow[b]{2}{*}{ Factor } & \multirow[b]{2}{*}{ Mean } & \multirow[b]{2}{*}{ Rank } & \multicolumn{6}{|c|}{ Component } \\
\hline & & & 1 & 2 & 3 & 4 & 5 & 6 \\
\hline b12 & 5.20 & 1 & 0.82 & & & & & \\
\hline b11 & 4.63 & 3 & 0.75 & & & & & \\
\hline b19 & 4.70 & 2 & 0.71 & & & & 0.34 & \\
\hline b16 & 4.18 & 10 & 0.66 & & & & & \\
\hline b18 & 4.40 & 5 & 0.56 & & & & & \\
\hline b17 & 4.33 & 6 & 0.52 & & & & & \\
\hline b09 & 4.24 & 9 & & 0.79 & & & & \\
\hline b07 & 4.58 & 4 & & 0.74 & & & & \\
\hline b01 & 3.97 & 16 & & 0.72 & & 0.39 & & \\
\hline b02 & 3.82 & 20 & & 0.69 & & & & \\
\hline b28 & 3.15 & 28 & 0.36 & 0.51 & 0.51 & & & \\
\hline b05 & 3.84 & 19 & & 0.46 & & & 0.42 & 0.34 \\
\hline b13 & 3.74 & 21 & & & 0.82 & & & \\
\hline b27 & 3.38 & 26 & & 0.42 & 0.65 & & 0.33 & \\
\hline b14 & 3.93 & 17 & 0.38 & & 0.65 & & & \\
\hline b10 & 3.47 & 24 & & & 0.63 & & & \\
\hline b08 & 4.02 & 14 & & 0.41 & 0.54 & & & 0.35 \\
\hline b23 & 3.25 & 27 & & 0.38 & 0.50 & 0.32 & 0.42 & \\
\hline b21 & 3.72 & 22 & & & & 0.83 & & \\
\hline b22 & 3.57 & 23 & & & & 0.83 & & \\
\hline b20 & 3.45 & 25 & & 0.32 & 0.32 & 0.71 & & \\
\hline b15 & 4.03 & 13 & 0.48 & & & 0.56 & & \\
\hline b26 & 4.28 & 8 & & & & & 0.70 & \\
\hline b03 & 4.30 & 7 & 0.48 & & & & 0.67 & \\
\hline b24 & 4.11 & 11 & & & & 0.31 & 0.60 & \\
\hline b25 & 4.07 & 12 & & & 0.31 & & 0.54 & 0.42 \\
\hline b04 & 3.98 & 15 & & & & & & 0.78 \\
\hline b06 & 3.85 & 18 & & 0.38 & & & & 0.52 \\
\hline Eigenvalue & & & 4.10 & 3.83 & 3.50 & 3.19 & 2.75 & 1.80 \\
\hline$\%$ of variance & & & 14.64 & 13.67 & 12.51 & 11.38 & 9.80 & 6.43 \\
\hline Cumulative $\%$ & & & 14.64 & 28.32 & 40.83 & 52.21 & 62.01 & 68.45 \\
\hline
\end{tabular}

Note: See Appendix A for details of each factor. Rotation converged in eight iterations. Kaiser-Meyer-Olkin measure of sampling adequacy was 0.841 . Bartlett's test of sphericity: approximate $\chi^{2}=1614$, $\mathrm{df}=378, p<$ 0.000 .

Moreover, clearly defined issue-resolution mechanisms with appropriate contractual arrangements reduce the occurrence of construction disputes and smooth relationships among contracting parties (Revay 1995).

Mutual trust (a07) and teamworking and can-do spirit (a10) are fundamental to building relationships among contracting parties (component 4: relationship-building protocols), with operational arrangements like open communication (a06) and effective coordination (a08). These are essential elements in RC-based approaches (Mohr and Spekman 1994; Bayramoglu 2001; Chan et al. 2004; Cheng and Li 2004). Component 5 (resource utilization) indicates that "experienced" (a05) parties can better utilize their "resources" (a12) that they mobilize/invest in a project.

\section{Factors deterring relational contracting}

In addition to means and ranks of individual factors in the total sample, Table 4 summarizes the outcomes from factor analysis for factors deterring RC. It is seen that "lack of trust" (b12, score 5.20) is the most important factor that deters RC, followed by "lack of confidence" (b19) and "team- working spirit" (b11) among all parties and "commitment of top management" (b07). "Absence of risk-reward plan" (b06, rank 18) is relatively less important. Exclusion of "subcontractors" (b21, rank 22), "suppliers" (b22, rank 23), and "consultants" (b20, rank 25) in any risk-reward plan are far less important than "unwilling participation" (b18, rank 5), "lack of experience in RC approaches" (b17, rank 6), "improper risk allocation" among contracting parties (b03, rank 7), and "separate coordination and monitoring plans" (b16, rank 10). This trend of importance of various factors may be taken to imply the option for structured RC approaches only between clients and contractors and with improvements in contractual responsibility allocation. "Incompatible public sector rules and regulations" (b28) is seen as the least important factor that deters RC, however. This is also the only insignificant factor in terms of the total (collective) sample, although all 28 factors are significant within different groups of respondents.

The ranks of individual factors within the contractors group are almost similar to those of the total sample, but considerably different from those of consultants and clients. 
Table 5. Importance and factor analysis outcomes of factors facilitating the "building of integrated project teams."

\begin{tabular}{|c|c|c|c|c|c|c|c|}
\hline \multirow[b]{2}{*}{ Factor } & \multirow[b]{2}{*}{ Mean } & \multirow[b]{2}{*}{ Rank } & \multicolumn{5}{|c|}{ Component } \\
\hline & & & 1 & 2 & 3 & 4 & 5 \\
\hline $\mathrm{c} 26$ & 3.45 & 28 & 0.77 & & & & \\
\hline $\mathrm{c} 27$ & 3.78 & 25 & 0.74 & & & & \\
\hline $\mathrm{c} 25$ & 4.08 & 15 & 0.74 & & & & \\
\hline $\mathrm{c} 06$ & 3.91 & 21 & 0.73 & & & & \\
\hline $\mathrm{c} 04$ & 3.66 & 26 & 0.73 & & 0.45 & & \\
\hline $\mathrm{c} 21$ & 3.63 & 27 & 0.69 & & & & \\
\hline $\mathrm{c} 05$ & 3.86 & 22 & 0.65 & & 0.32 & 0.40 & \\
\hline $\mathrm{c} 24$ & 4.22 & 8 & 0.58 & & & & 0.46 \\
\hline $\mathrm{c} 14$ & 3.81 & 24 & 0.49 & & 0.32 & 0.42 & \\
\hline $\mathrm{c} 10$ & 4.17 & 12 & & 0.78 & & & \\
\hline $\mathrm{c} 11$ & 4.20 & 9 & & 0.71 & & & \\
\hline $\mathrm{c} 12$ & 4.18 & 11 & & 0.69 & & & \\
\hline $\mathrm{c} 07$ & 4.13 & 13 & & 0.63 & & 0.37 & \\
\hline $\mathrm{c} 13$ & 3.96 & $18 \mathrm{e}$ & 0.48 & 0.61 & & & \\
\hline $\mathrm{c} 08$ & 4.48 & 2 & & 0.55 & & 0.52 & \\
\hline $\mathrm{c} 18$ & 4.11 & 14 & 0.36 & 0.54 & & & \\
\hline $\mathrm{c} 01$ & 3.96 & $18 \mathrm{e}$ & & & 0.83 & & \\
\hline $\mathrm{c} 02$ & 3.84 & 23 & 0.37 & & 0.81 & & \\
\hline $\mathrm{c} 03$ & 4.00 & 17 & 0.34 & & 0.75 & & \\
\hline $\mathrm{c} 16$ & 4.19 & 10 & 0.32 & & & 0.70 & 0.36 \\
\hline $\mathrm{c} 15$ & 4.39 & 4 & & & & 0.64 & \\
\hline $\mathrm{c} 17$ & 4.44 & 3 & & & & 0.59 & 0.54 \\
\hline $\mathrm{c} 20$ & 4.03 & 16 & 0.36 & & & 0.56 & \\
\hline $\mathrm{c} 09$ & 4.53 & 1 & & & 0.51 & 0.54 & \\
\hline $\mathrm{c} 23$ & 4.24 & $6 e$ & & & & & 0.76 \\
\hline $\mathrm{c} 22$ & 3.93 & 20 & & & & & 0.69 \\
\hline $\mathrm{c} 19$ & 4.24 & $6 e$ & & & & 0.39 & 0.58 \\
\hline $\mathrm{c} 28$ & 4.35 & 5 & 0.45 & 0.35 & & & 0.53 \\
\hline Eigenvalues & & & 5.50 & 3.61 & 3.12 & 3.10 & 2.84 \\
\hline$\%$ of variance & & & 19.63 & 12.90 & 11.15 & 11.06 & 10.15 \\
\hline Cumulative $\%$ & & & 19.63 & 32.53 & 43.68 & 54.74 & 64.89 \\
\hline
\end{tabular}

Note: See Appendix A for details of each factor. The letter "e" after a rank signifies equal rank and the next $\operatorname{rank}(\mathrm{s})$ is (are) omitted, except the lowest rank where the previous rank(s) is (are) omitted. Rotation converged in seven iterations. Kaiser-Meyer-Olkin measure of sampling adequacy was 0.857 . Bartlett's test of sphericity: approximate $\chi^{2}=1624$, df $=378, p<0.000$.

For contractors, the highest score is higher and the lowest score is lower than those of the other two groups of respondents. The ranks of different factors within the consultants and clients groups are mostly different, but their scores are closer: the highest and lowest scores are 5.00 and 3.95, respectively, for consultants and 4.93 and 3.73, respectively, for clients; but those for contractors are 5.40 and 2.48 , respectively. Accordingly, ANOVA results indicated that clients and consultants have similar perceptions of all the 28 factors, but contractors have perceptions of nine and 12 factors similar to those of consultants and clients, respectively. On the whole, the three groups of respondents significantly agree on the importance levels of nine factors only.

The factor analysis exercise extracted six interrelated components (see Table 4), and together they explained over $68 \%$ of the total variation. Fourteen factors (out of 28, or $50 \%$ ) are seen to contribute to more than one component, and even up to four components: factor b23 (unrelated/ separate risk-reward plans for different parties) contributes to components $2,3,4$, and 5, with factor loadings of 0.38 , $0.50,0.32$, and 0.42 , respectively.

Component 1 (lack of relationship-building protocols) consists of primary contributions of six factors and secondary contributions of four factors. This component explains that lack of "trust" (b12, b19) and "teamworking attitude" (b11) can lead to "unenthusiastic participation" of the parties in RC approaches, which is not productive for these approaches (Mohr and Spekman 1994). In particular, a very important consequence of unwilling commitment is the erosion of trust (Antich 2005). This can be aggravated by "separate coordination and monitoring plans" (b16). "Experience" (b17) may overcome such barriers, however. Component 2 (lack of top management support and appropriate planning) explains that lack of support from top management (b07) restricts any amendment to "incompatible public sector rules and regulations" (b28), which are mainly responsible for "inappropriate project planning" (b01) and selection of "inappropriate procurement/contract strategy" (b02) with "unclear contract 
Table 6. Importance and factor analysis outcomes of factors deterring the "building of integrated project teams."

\begin{tabular}{|c|c|c|c|c|c|c|c|c|c|}
\hline \multirow[b]{2}{*}{ Factor } & \multirow[b]{2}{*}{ Mean } & \multirow[b]{2}{*}{ Rank } & \multicolumn{7}{|c|}{ Component } \\
\hline & & & 1 & 2 & 3 & 4 & 5 & 6 & 7 \\
\hline $\mathrm{d} 02$ & 4.31 & 7 & 0.88 & & & & & & \\
\hline $\mathrm{d} 03$ & 4.44 & 5 & 0.81 & & & & & & \\
\hline $\mathrm{d} 01$ & 3.81 & 21 & 0.76 & & & & & & \\
\hline $\mathrm{d} 04$ & 3.90 & 18 & 0.70 & & & & & & \\
\hline $\mathrm{d} 05$ & 3.31 & 28 & 0.65 & & & & 0.32 & 0.34 & \\
\hline $\mathrm{d} 29$ & 4.96 & 2 & & 0.86 & & & & & \\
\hline $\mathrm{d} 11$ & 5.11 & 1 & & 0.82 & & & & & 0.31 \\
\hline $\mathrm{d} 26$ & 4.56 & 3 & & 0.77 & & & & & \\
\hline $\mathrm{d} 28$ & 4.35 & 6 & & 0.72 & & & & & 0.34 \\
\hline $\mathrm{d} 12$ & 4.51 & 4 & 0.33 & 0.51 & & & & 0.34 & \\
\hline $\mathrm{d} 22$ & 3.79 & 23 & & & 0.88 & & & & \\
\hline $\mathrm{d} 23$ & 3.83 & 20 & & & 0.86 & & & & \\
\hline $\mathrm{d} 21$ & 3.88 & 19 & & & 0.83 & & & & \\
\hline $\mathrm{d} 24$ & 3.60 & $25 \mathrm{e}$ & 0.35 & & 0.59 & 0.39 & 0.30 & & \\
\hline $\mathrm{d} 18$ & 3.73 & 24 & & & & 0.87 & & & \\
\hline d19 & 3.60 & $25 \mathrm{e}$ & & & & 0.86 & & & \\
\hline $\mathrm{d} 17$ & 3.41 & 27 & 0.35 & & & 0.71 & & & \\
\hline $\mathrm{d} 25$ & 4.18 & 9 & & 0.44 & & 0.45 & & & \\
\hline $\mathrm{d} 16$ & 3.30 & 29 & 0.39 & & & 0.43 & 0.31 & & \\
\hline d09 & 4.00 & 14 & & & & & 0.68 & & \\
\hline $\mathrm{d} 10$ & 3.99 & 15 & 0.33 & & & & 0.61 & & \\
\hline $\mathrm{d} 13$ & 3.80 & 22 & & & & & 0.59 & 0.35 & \\
\hline $\mathrm{d} 14$ & 3.98 & 16 & & & & & 0.58 & 0.43 & \\
\hline $\mathrm{d} 27$ & 4.02 & 13 & & & & & 0.56 & & \\
\hline $\mathrm{d} 31$ & 4.28 & 8 & 0.30 & & 0.32 & & & 0.67 & \\
\hline $\mathrm{d} 08$ & 4.04 & 12 & & & & & & 0.57 & \\
\hline $\mathrm{d} 30$ & 4.08 & 11 & 0.41 & & & 0.32 & & 0.55 & \\
\hline $\mathrm{d} 07$ & 3.10 & 31 & 0.51 & 0.43 & & & & 0.53 & \\
\hline d06 & 3.11 & 30 & 0.47 & 0.43 & & & & 0.52 & \\
\hline $\mathrm{d} 15$ & 3.92 & 17 & & & & & 0.46 & 0.30 & 0.62 \\
\hline $\mathrm{d} 20$ & 4.09 & 10 & & 0.38 & & & 0.32 & & 0.57 \\
\hline Eigenvalues & & & 4.74 & 4.02 & 3.49 & 3.39 & 3.09 & 2.77 & 1.35 \\
\hline$\%$ of variance & & & 15.30 & 12.97 & 11.26 & 10.94 & 9.97 & 8.92 & 4.35 \\
\hline Cumulative $\%$ & & & 15.30 & 28.27 & 39.53 & 50.47 & 60.44 & 69.36 & 73.71 \\
\hline
\end{tabular}

Note: See Appendix A for details of each factor. The letter "e" after a rank signifies equal rank and the next $\operatorname{rank}(\mathrm{s})$ is (are) omitted, except the lowest rank where the previous rank(s) is (are) omitted. Rotation converged in 25 iterations. Kaiser-Meyer-Olkin measure of sampling adequacy was 0.847 . Bartlett's test of sphericity: approximate $\chi^{2}=2254, \mathrm{df}=465, p<0.000$.

documents" (b05). In such scenarios, even a capable contractor cannot perform satisfactorily (b09) (Rahman and Kumaraswamy 2004a).

Component 3 (lack of client initiative and cultural barrier) indicates that "bureaucratic clients" (b27) lack "initiatives" (b08) of overcoming cultural clashes both at "individual" (b13) and "organizational" (b14) levels. Such clients use "separate risk-reward plans for different parties" (b23), which may lack any "scope for innovations" (b10) as well. This is consistent with previous findings in Canada that the industry is hesitant to move away from traditional lump-sum lowest bid contracts (Dozzi et al. 1996). Component 4 (incomplete risk-reward scheme) highlights that exclusion of "consultants" (b20) and major "subcontractors" (b21) and "suppliers" (b22) may lead to devising "inappropriate issueresolution mechanisms" (b15). "Persisting adversarial setting" (component 5) indicates that participating in contracts with "improper risk allocation" (b25) may create extra "commercial pressure" (b25) on the contracting parties, which may push them to a clear "win-lose environment" (b26) and provoke their concerns on "legal liabilities" (b24) in resolving noncontractual issues. This is also consistent with Canadian experience (Dozzi et al. 1996; Hartman et al. 1997). Lastly, component 6 (persisting price-based selection) points to the fact that "price only" selection methods (b04) probably lack any "risk-reward plan" (b06) (Dozzi et al. 1996).

\section{Factors facilitating the building of integrated project teams for relational contracting}

Singapore respondents consider that "willingness/enthusiasm of involved parties" (c09) is the most important factor that facilitates building integrated project teams for effective RC (see Table 5). The score for this highest ranked factor is 
4.53, which is also seen to be the lowest score among the top-ranked factors of the four categories. The next two most important factors within this category are "reputation in the industry" (c08) and "disclosing project information to potential partners at early stages of project for any optional feedback" (c17). "Corporate strategy of building trust with potential partners" (c28) is the fifth most important factor. Instead of "price only" considerations, respondents prioritize that "selection of project team members" (c16, rank 10) should be based on ( $i$ ) their ability to carry out the proposed works in terms of "resources and technical skills" (c11, rank 9) and "previous performance records on hard factors" (c12, rank 11), and (ii) an estimation of "compatibility" to harmoniously work with other contracting parties in terms of "performance records on relational factors" (c15, rank 4) and cultural harmony both at "corporate" (c13, rank 18) and "personal" (c14, rank 24) levels. "Enlightened" (c01, rank 18) and "knowledgeable" (c02, rank 23) clients are relatively less important. Thus, soft or relational factors are seen to top the list. The trend is followed by factors related to team-building and (or) team selection, with an emphasis on using soft or relational qualities.

"Requirement for an independent full-time facilitator to supplement project manager" (c26) is the least important factor, with a score of 3.45 , which is more than the average of the measuring scale. This also implies a general importance of all 28 factors. This is confirmed by the one-sample $t$ test results: all 28 factors are significant for building integrated project teams, both in the total sample and within different groups of respondents. The corresponding highest and lowest scores, respectively, are 4.60 and 3.18 for the contractors, 4.81 and 3.81 for the consultants, and 4.73 and 3.53 for the clients. Except for a very few, however, the ranks of individual factors within different respondent groups are different. Accordingly, ANOVA results indicated that the three groups of respondents have similar perceptions of 17 factors only, although contractors significantly agree with consultants on 16 factors and with clients on 20 factors. Clients and consultants have similar perceptions of all 28 factors. Further examination revealed some interesting insights. The factor "enlightened and enthusiastic client" (c01) ranks 1 in the clients group, 7 in the consultants group, 23 in the contractors group, and 18 in the total sample. Their corresponding scores are 4.73, 4.43, 3.60, and 3.96. Thus the ranks differ considerably. The scores of this factor in clients and consultants groups are sufficiently close, but the score in the contractors group is sufficiently different that only clients and consultants groups significantly agree on the importance level of this factor.

On the other hand, the factor "resources and technical skills" (c11) ranks 7 in the clients group, 18 in the consultants group, 11 in the contractors group, and 9 in the total sample. Their corresponding scores are 4.40, 4.24, 4.13, and 4.20. Thus, the ranks differ considerably, but the scores are close, so that all the respondent groups significantly agree on the importance level of this factor. A third scenario is that both the ranks and scores are sufficiently closer and the respondent groups significantly agree on the importance level. For example, the factor c18 (seeking specific inputs on constructibility, construction methods, materials, etc., from among potential partners for better project planning at the precontract stage) ranks 12 in the clients group, 12 in the consultants group, 13 in the contractors group, and 14 in the total sample. Their corresponding scores are 4.27, 4.29, 4.02, and 4.11.

The factor analysis exercise extracted five interrelated components (Table 5) with both primary and secondary contributions from different factors. As such, 16 factors (out of 28 , or $57 \%$ ) contribute to more than one component and up to three components. Some of them contribute almost equally to more than one component, such as c08 (reputation in the industry), c09 (willingness/enthusiasm of involved parties), and c17 (disclosing project information to potential partners at early project stages for any optional feedback) (see Table 5). All these clearly suggest a consolidated but interrelated approach. Moreover, three of the five components clearly hinge on the selection-related issues, as discussed in the following.

Component 1 (overall learning and facilitating environment) explains that an appropriate "training policy" (c27) of a construction organization can help its employees learn about "RC approaches" (c04) and "working in flexible contracts" (c05) before contracting and develop "harmonious interpersonal relations" building skills. Glagola and Sheedy (2002) argue that training the people is the best way to overcome barriers like an adversarial mindset, fear of the unknown, and working in a changing situation. A demonstration of the underlying principles, along with related benefits that have been documented with RC approaches, can motivate people to attain mutual trust. Project participants with such skills, in addition to the facilitating leadership of the project manager in building and guiding the project team (c24, c25, c26) and team-building protocols like "workshops" (c21) (Jergeas 2004), can help to guide the project organization into a "cooperative learning" (c06) mode.

Component 2 (building capable and compatible project team) explains that building an effective project team requires selection considerations from both technical and relational aspects. Technical aspects include "adequate resources and technical skills" (c11) and "performance records on hard factors" (c12). Relational aspects of the participating parties include "reputation in the industry" (c08), "experience in RC approaches" (c10), "familiarity/previous relationships" (c07), and "compatible organizational culture" (c13). This component also infers that clients can seek specific inputs on constructibility, construction methods, materials, etc. from among such potential partners (c18) that will help them to foster better project planning. Component 3 (enlightened and knowledgeable client) explains that a "knowledgeable client" (c02) can better streamline his or her "enlightened and enthusiastic" (c01) "initiatives" (c03) towards building an integrated project team. This is critical for building an integrated project team, since clients effectively control the team selection process, project organization, and contract contents (Dozzi et al. 1996; Rahman and Kumaraswamy 2004b).

Component 4 (improved selection and mobilization methodologies) explains that "enthusiasm" (c09) and "performance records" on relational aspects (c15) are important for team-building and refers to considering the "capability and compatibility" (c16) from the viewpoint of the proposed team, instead of "price only" considerations. Clients can disclose project information to such potential partners for any 
feedback (c17) and bring them into the project team for better integration (c20), at early stages of the project, if appropriate (Rahman and Kumaraswamy 2005a). Component 5 (innovative responsibility allocation and appropriate team selection) explains that when the best possible "capable and compatible" project team is selected from among potential partners (c19), with "corporate strategy of building trust with potential partners by doing the right things and meeting time and cost targets" (c28), members of such a project team may assume "combined" (c23) and "single point" (c22) responsibility for the project team as a whole.

\section{Factors deterring the building of integrated project teams for relational contracting}

"Lack of trust" (d11, score 5.11) is seen as the most important factor that deters the building of integrated project teams for RC, followed by "discontinuation of open and honest communication" (d29, rank 2), "failure to share information among contracting parties" (d26, rank 3), and "unwilling participation" (d12, rank 4). "Lack of commitment from top management" ( $\mathrm{d} 02, \mathrm{~d} 03$ ) of other parties (rank 5) and clients (rank 7) is relatively more important than lack of client's "initiatives" (d04, rank 19) and "knowledge" (d01, rank 21). On the other hand, "bureaucratic client organization" (d05, rank 28) is far less important than "uneven commitment" (d28, rank 6) and "improper planning, design errors and omissions" (d30, rank 11). "Lack of relationships/communications between clients and subcontractors" (d21, rank 19), "lack of relationships/communications between consultants and suppliers (d23, rank 20), "lack of relationships/communications between client and suppliers" (d22, rank 23), and "lack of relationships/communications between subcontractors and suppliers" (d24, rank 25) are less important. Exclusion of consultants (d17, rank 27), subcontractors (d18, rank 24) and suppliers (d19, rank 25) in risk-reward plan are also less important. "Public sector accountability concerns" (d07) is the least important factor that deters the building of integrated project teams for RC in Singapore. The 3.10 score for this factor (more than the average of the measuring scale) also implies a general importance of all 31 factors used in the survey. This is confirmed by the significance levels obtained from the $t$ tests: all the factors are significant both within each respondent group and within the total sample.

ANOVA results indicated that clients and consultants have similar perceptions of all 31 factors, except "lack of contractual relations between clients and major subcontractors" (d21). The rank of this factor is 1 (score 4.80) within the clients group and 30 (score 3.90) within the consultants group. Except for a few, the ranks of other factors within these two groups of respondents are different, but their scores are close. For example, the score of the factor "bureaucratic client organization" (d05) is 8 and 24 within the consultants and clients groups, respectively, with corresponding scores of 4.43 and 4.00. Contractors have similar perceptions of only 10 factors with both consultants and clients, however, of which eight factors are common. Ranks of different factors within the contractors group are the same as or close to the ranks within the total sample but are considerably different from those within the consultants and clients groups. As such, the three groups of respondents have similar perceptions of eight factors only.

The factor analysis exercise extracted seven interrelated components, and together they explained over $73 \%$ of variations. A total of 17 (out of 31 , or $55 \%$ ) factors are seen to contribute to more than one component (see Table 6), and factor d24 (lack of relationships/communications between subcontractors and suppliers) contributes to four components, with factor loadings of $0.35,0.59,0.39$, and 0.30 to components $1,3,4$, and 5, respectively. On the whole and as in the other three categories of factors, the factor analysis results for this category also suggest the need for a consolidated and interrelated approach.

Component 1 (lack of top management and cliental support) explains that the "lack of commitment from top management" (d02, d03) deters building of integrated project teams. It also explains that "bureaucratic" (d05) behaviour of cliental organizations may prevent them from attaining appropriate "knowledge about project processes" (d01) and "initiatives" (d04) about RC, which can be overcome with top management support. Component 2 (lack of trust and willingness) explains that "lack of trust" (d11), "unenthusiastic participation" (d12), and "uneven commitment" (d28) may lead to discontinuation of "open and honest communication" (d29) and "information sharing" (d26) among the contracting parties, which in turn deter the building of integrated project teams.

Component 3 (incomplete relationships/communications) explains the lack of relationships within the project team and points to the "absence of contractual relations between client and major subcontractors" (d21). This component also points to the lack of relationships/communications between "client and major suppliers" (d22), "consultants and suppliers" (d23), and "subcontractors and suppliers" (d24). Component 4 (lack of integrated risk-reward scheme) explains the exclusion of "consultants" (d17), "subcontractors" (d18), and "suppliers" (d19) in any risk-reward plan of the project and (or) the use of "separate/unrelated risk-reward plans for different parties" (d16).

Component 5 (persisting adversarial environment) summarizes the potential adversarial environment within the project team that may arise from "interpersonal" (d13), or "corporate level" (d14) cultural clashes and (or) the existence of "master and slave" type behaviour (d27). Such environment and "commercial pressures" (d09) may invoke "opportunistic behaviour" (d10) of the contracting parties. Component 6 (regulatory barriers and accountability) explains that "public sector accountability concerns" (d07) require public clients to operate under certain rules and regulations that may be "stringent/incompatible" (d06) and support "price only selection methods" (d08). Parties win contracts under tough price competition with low profit margins, however, and their tendency to complete the tasks with minimum resources may lead to "improper planning, design errors and omissions" (d30), and parties may fear "potential legal liabilities" (d31) imposed by the aforementioned rules and regulations in resolving any conflicts that may arise from errors and omissions. Component 7 (lack of risk-reward plan) explains that "unfair" (d20) or "absence" (d15) of any risk-reward plan deters the building of integrated project teams for RC. 


\section{Analysis of survey results}

To provide both contractual and noncontractual incentives, the Singapore-based survey presented in this paper evaluated various factors and strategies for developing a deeper and wider RC culture and team-building in construction. This includes four categories of factors and strategies that $(i)$ facilitate RC, (ii) deter RC, (iii) facilitate the building of integrated teams for $\mathrm{RC}$, and (iv) deter the building of integrated teams for RC. The study recognized some general trends and revealed the positive attitudes of Singaporean industry participants towards both RC and team-building. These include the following.

(1) All the factors used in the survey are significant in their respective categories, except the factor "incompatible public sector rules and regulations" (b28). All the factors are also perceived to be important, of course, to different degrees. When compared pairwise, however, contractors significantly disagree with consultants and clients on the relative importance of most of the factors, but consultants and clients significantly share similar perceptions on all the factors used in the survey, except the factor "lack of contractual relations between clients and major subcontractors" (d21). When the three groups of respondents are considered together in one whole group, they significantly disagree on the relative importance of most of the factors used in this study.

(2) Trust and trust-based operational and contractual arrangements are seen as more important than some other factors that facilitate RC. The relative importance of different factors within this category indicates a tendency towards project-based postcontract partnering-type RC arrangements.

(3) Lack of trust and commitment related factors clearly top the list to indicate their prime importance in deterring $\mathrm{RC}$. The relative importance of other factors within this category seems to suggest a preference for structured exercise of RC approaches between clients and contractors with improvements in contractual responsibility allocation. Thus, the facilitating and deterring factors for $\mathrm{RC}$ may be considered to be complementary.

(4) Willingness and reputation are seen to top the list within the category of factors facilitating the building of integrated project teams for RC. The priority is seen to be placed on selecting the team, however, with an emphasis on soft or relational qualities.

(5) Lack of trust, trust-based operational arrangements, and commitment are more important than all other deterring factors for building integrated teams. The relative importance of other factors indicates an emphasis of integration only between clients and contractors, however. Thus, only several top-ranked factors in the two categories (of facilitating and deterring factors for building integrated project teams) may be considered as complementary, since all those are soft or relational qualities. The importance of other factors within these two categories indicates the main preference of selecting the "main" contractors for building integrated project teams for RC.

(6) If the two categories of facilitating factors are considered together, trust and other relational qualities are clearly seen as "most" important for integration in con- struction. The present perceptions of Singaporean industry participants appear to envisage such integration through trust-based operational and contractual arrangements, and extended use of relational qualities in team selection, for postcontract partnering-type RC arrangements between clients and contractors.

(7) Between the two categories of deterring factors, a similar broad trend of importance of various factors has been perceived. Lack of trust and lack of commitment are seen as the most important barriers for integration in the Singapore construction industry. The trend is followed by a perceived need for improvement in responsibility allocation and operational arrangements (e.g., risk allocation/sharing, communication and information sharing, risk-reward plan). Similar to the facilitating factors, such exercises have clearly been preferred only between clients and contractors.

(8) In terms of importance of different factors, both for RC and team-building, the findings are consistent with those of relevant previous studies in Canada (e.g., Revay 1995; Dozzi et al. 1996; Hartman et al. 1997; Jergeas and Revay 1999; Jergeas 2004) and elsewhere (e.g., Baker 1990; Mohr and Spekman 1994; Larson 1995; Egan 1998; Black et al. 2000; Glagola and Sheedy 2002; Chan et al. 2004).

(9) Interesting outcomes of this study originated from factor analysis, suggesting a consolidated but interrelated approach, both for RC and integrated project teams. At least half of the factors are seen to play multiple roles in each category of factors with their primary and secondary contributions to all the components. Several factors even contribute to four components. Also, some factors contribute either equally or almost equally to more than one component, but the extracted smaller numbers of representative "broad factors" or "components" are named according to their primary contributing factors, which are summarized in Table 7.

\section{Conclusions}

True "integration" in construction projects implies mobilization of collaborative efforts from project team members and continuity of their harmonious relationships during project execution to ensure value for money and optimized project delivery. This requires construction contracts to provide opportunities for appropriate protocols. As such, various factors and strategies were identified to assess their relative importance and to offer any contractual or noncontractual incentives for designing appropriate RC-based project teams.

Data were collected from the Singaporean construction industry and statistically analyzed. The results show that all the factors and strategies suggested in the survey are important to different degrees and that all the factors used in the survey are significant within their respective categories, except for just one (b28: incompatible public sector rules and regulations). When different groups of respondents are compared pairwise, consultants and clients are seen to significantly share similar perceptions of all the factors, except factor d21 (lack of contractual relations between clients and major subcontractors). On the contrary, contractors significantly disagree with consultants and clients on the relative 
Table 7. Summary of factor analysis results.

Components from facilitating factors

\section{Relational contracting (RC)}

1. Client and top management support

2. Appropriate contractual incentives

3. Alignment of team objectives

4. Relationship-building protocols

5. Resource utilization
Components from deterring factors

1. Lack of relationship-building protocols

2. Lack of top management support and appropriate planning

3. Lack of client initiative and cultural barrier

4. Incomplete risk-reward scheme

5. Persisting adversarial setting

6. Persisting price-based selection

\section{Integrated team}

1. Overall learning and facilitating environment

2. Building capable and compatible project team

3. Enlightened and knowledgeable client

4. Improved selection and mobilization methodologies

5. Innovative responsibility allocation and appropriate team selection
1. Lack of top management and client support

2. Lack of trust and willingness

3. Incomplete relationships/communications

4. Lack of integrated risk-reward scheme

5. Persisting adversarial environment

6. Regulatory barriers and accountability

7. Lack of risk-reward plans importance of most of the factors. When all of the respondents are taken together in one group, they significantly disagree on the relative importance of most of the factors. This may be partially explained by the fact that there are more contractors $(n=60)$ in the whole group than consultants $(n=$ $21)$ and clients $(n=15)$.

Despite the obvious aforementioned differences, it was observed that trust and trust-based operational and contractual arrangements can effectively provide the required incentives for the Singaporean construction industry (in its present state) to launch postcontract partnering-type RC arrangements between clients and contractors, and through extended attention to "relational" qualities in selection. Based on the overall responses, it was also noted that both pairs of facilitating and deterring factors largely complement each other. Moreover, both pairs of facilitating and deterring categories of factors exhibit a similar broad trend of importance of the various factors, indicating that $\mathrm{RC}$ and team-building complement each other, at least to some extent.

The factor analysis exercise extracted five components for representing factors facilitating $\mathrm{RC}$, six components for factors deterring $\mathrm{RC}$, five components for factors facilitating building integrated project teams for $\mathrm{RC}$, and seven components for factors deterring building integrated project teams for RC. At least half of the factors in each category were observed to play multiple roles, a few factors contribute to four components, and a few other factors contribute equally or almost equally to more than one component. This suggests the usefulness of highly interrelated and consolidated strategies and approaches, both for developing a culture of $\mathrm{RC}$ and for building integrated project teams in the Singaporean construction industry.

Apart from Singapore, the findings from this study should be of interest to many other countries, including Canada, where "similar" scenarios may be recognized, e.g., in terms of industry experiences and maturity levels. This is heightened by the increased "globalization" of construction industries through the enhanced mobility of construction organizations (including contractors, consultants, suppliers, and even clients such as airport authorities and railway corporations). The relevance of the findings is further enhanced by the fact that the Singaporean construction industry itself includes many construction organizations with "overseas" origins and hence should incorporate a cross section of some international experience. Furthermore, the methodology and tools developed for this study may also provide the basis for designing and launching similar studies in other construction industries, which may be perceived to be considerably different, e.g., in terms of maturity levels, strengths, weaknesses, and priorities.

\section{Acknowledgement}

Grant HKU/7011/02E from the Hong Kong Research Grants Council is gratefully acknowledged for facilitating this research.

\section{References}

Antich, T. 2005. Make and keep commitments at work. Leadership and Management in Engineering, 5(1): 12-14.

Baker, S.T. 1990. Partnering: contracting for the future. Cost Engineering, 32(4): 7-12.

Bayramoglu, S. 2001. Partnering in construction: improvement through integration and collaboration. Leadership and Management in Engineering, 1(3): 39-43.

Black, C., Akintoye, A., and Fitzgerald, E. 2000. An analysis of success factors and benefits of partnering in construction. International Journal of Project Management, 18(6): 423-432.

CCE. 1994. Also, recession? What recession? (CEO workshop). Canadian Consulting Engineer (CCE), 1994(Nov.-Dec.): 15.

CCE. 1995. The future: not what it used to be. Canadian Consulting Engineer (CCE), 1995(May-June): 38.

Chan, A.P.C., Chan, D.W.M., Chiang, Y.H., Tang, B.S., Chan, E.H.W., and Ho, K.S.K. 2004. Exploring critical success factors for partnering in construction projects. ASCE Journal of Construction Engineering and Management, 130(2): 188-198.

Cheng, E.W.L., and Li, H. 2002. Construction partnering process and associated critical success factors: quantitative investigation. ASCE Journal of Management in Engineering, 18(4): 194-202.

Cheng, E.W.L., and Li, H. 2004. Development of a practical model of partnering for construction projects. ASCE Journal of Construction Engineering and Management, 130(6): 790-798. 
CIRC. 2001. Construct for excellence. Construction Industry Review Committee (CIRC), Hong Kong.

Construction 21. 1999. Re-inventing construction. Ministry of Manpower and Ministry of National Development, Singapore.

Dozzi, P., Hartman, F., Tidsbury, N., and Ashrafi, R. 1996. More stable owner-contractor relationships. ASCE Journal of Construction Engineering and Management, 122(1): 30-35.

Egan, J. 1998. Rethinking construction. Construction Task Force (CTF) Report, Department of the Environment, Transport and the Regions, London, UK.

Glagola, C.R., and Sheedy, W.M. 2002. Partnering on defense contracts. ASCE Journal of Construction Engineering and Management, 128(2): 127-138.

Hartman, F., Snelgrove, P., and Ashrafi, R. 1997. Effective wording to improve risk allocation in lump sum contracts. ASCE Journal of Construction Engineering and Management, 123(4): 379-387.

Jergeas, G. 2004. How to build and sustain project teams [online]. In Proceedings of the 84th APEGGA Annual Conference, Edmonton, Alta., 22-23 April 2004. Association of Professional Engineers, Geologist, and Geophysicists of Alberta (APEGGA), Edmonton, Alta. Available from [accessed 28 June 2006].

Jergeas, G.F., and Revay, S.O. 1999. An integrated value management approach. AACE International Transactions, PM12: 1-4.

Larson, E. 1995. Project partnering: results of study of 280 construction projects. ASCE Journal of Management in Engineering, 11(2): 30-35.

Lyons, B., and Mehta, J. 1997. Private sector business contracts: the text between the lines. In Contracts, cooperation, and competition: studies in economics, management, and law. Edited by S. Deakin and J. Michie. Oxford University Press, Oxford, UK. pp. 43-66.

Macneil, I.R. 1974. The many futures of contract. Southern California Law Review, 47(3): 691-816.

Mohr, J., and Spekman, R. 1994. Characteristics of partnership success: partnership attributes, communication behavior, and conflict resolution techniques. Strategic Management Journal, 15(2): 135-152.

PSIB. 2004. Inventory of international reforms in building and construction. Publication PSIB017-S-04-2341, Process and System Innovation in Building and Construction (PSIB) Programme, Government Building Agency, the Netherlands Government, The Hague, The Netherlands.

Rahman, M.M. 2003. Revitalising construction project procurement through joint risk management. Ph.D. thesis, Department of Civil Engineering, The University of Hong Kong, Hong Kong.

Rahman, M.M., and Kumaraswamy, M.M. 2002a. Joint risk management through transactionally efficient relational contracting. Construction Management and Economics, 20(1): 45-54.

Rahman, M.M., and Kumaraswamy, M.M. 2002b. Risk management trends in the construction industry: moving towards joint risk management. Engineering, Construction and Architectural Management, 9(2): 131-151.

Rahman, M.M., and Kumaraswamy, M.M. 2004a. Contracting relationship trends and transitions. ASCE Journal of Management in Engineering, 20(4): 147-161.

Rahman, M.M., and Kumaraswamy, M.M. 2004b. Potential for implementing relational contracting and joint risk management. ASCE Journal of Management in Engineering, 20(4): 178-189.

Rahman, M.M., and Kumaraswamy, M.M. 2005a. Assembling integrated project teams for joint risk management. Construction Management and Economics, 23(4): 365-375.

Rahman, M.M., and Kumaraswamy, M.M. 2005b. Relational selection for collaborative working arrangements. ASCE Journal of Construction Engineering and Management, 131(10): 1087-1098.
Revay, S. 1995. Can construction disputes be avoided? The Revay Report, 14(2): 1-4.

SPSS Inc. 2003. Statistical package for the social sciences. Version 12.0 [computer program]. SPSS Inc., Chicago, Ill.

Zaghloul, R., and Hartman, F. 2003. Construction contracts: the cost of mistrust. International Journal of Project Management, 21(6): 419-424.

\section{Appendix A}

Factors facilitating relational contracting (category one)

The factors facilitating $\mathrm{RC}$ are as follows: (a01) enlightened and enthusiastic client; (a02) knowledgeable client (about project processes); (a03) client's top management support; (a04) top management support of all contracting parties; (a05) experience in RC approaches (e.g., partnering, alliancing); (a06) open communication among all contracting parties; (a07) mutual trust among all contracting parties; (a08) effective coordination among all contracting parties; (a09) combined responsibility of all contracting parties; (a10) teamworking and "can do" spirit of all contracting parties; (a11) long-term commitment to each other (all parties); (a12) adequate resources of all contracting parties; (a13) mutually agreed issue-resolution mechanisms; (a14) mutually agreed performance appraisal mechanisms; (a15) alignment of project objectives of different parties; (a16) alignment of commercial objectives of different parties; (a17) alignment of mutual project and commercial objectives; (a18) learning climate/environment in project team organization; (a19) positive attitude towards continuous improvement; (a20) clearly defined risk allocation/sharing arrangements; (a21) equitable risk allocation/sharing arrangements; (a22) flexible/adjustable contracts to address uncertainties; (a23) encouraging and motivating risk-reward plans; (a24) inclusion of all key parties in risk-reward plans.

\section{Factors inhibiting relational contracting (category two)}

The factors inhibiting RC are as follows: (b01) inappropriate project planning; (b02) inappropriate procurement/contract strategy; (b03) improper/inappropriate risk allocation/sharing; (b04) "price only" selection methods; (b05) ambiguous/ unclear contract clauses/documents; (b06) absence of riskreward plan; (b07) lack of commitment from top management of all contracting parties; (b08) lack of client's initiatives; (b09) lack of contractor's capability; (b10) lack/absence of scope for innovations; (b11) lack of teamworking attitude among all contracting parties; (b12) lack of trust/reliability among all contracting parties; (b13) interpersonal/cultural clash (individual level); (b14) incompatible organizational cultures (corporate level); (b15) inappropriate issue-resolution mechanisms; (b16) separate coordination and monitoring plans; (b17) lack of experience in RC approaches (e.g., partnering); (b18) unwilling/unenthusiastic participation in $\mathrm{RC}$ approaches; (b19) lack of confidence among all contracting parties; (b20) exclusion of consultants in risk-reward plan; (b21) exclusion of major subcontractors in risk-reward plan; (b22) exclusion of major suppliers in risk-reward plan; (b23) unrelated/separate risk-reward plans for different parties; (b24) potential legal liabilities (in resolving noncontractual issues); (b25) commercial pressures of contracting parties; (b26) win-lose environment among contracting parties; (b27) 
bureaucratic client organization; (b28) incompatible public sector rules and regulations.

\section{Factors facilitating building a project-based integrated team for more effective relational contracting (category three)}

The factors facilitating building a project-based integrated team for more effective RC are as follows: (c01) enlightened and enthusiastic client; (c02) knowledgeable client (about project processes and RC); (c03) client's initiative; (c04) learning about RC approaches before contracting (all parties), e.g., at a workshop, seminar, or training within the company; (c05) learning working in flexible contract/ teamworking environment before contracting with others (all parties), e.g., through training; (c06) cooperative learning within project organization; (c07) familiarity/previous relationships with/among other parties; (c08) reputation in the industry (each party); (c09) willingness/enthusiasm of involved parties; (c10) previous experience in RC approaches (each party); (c11) adequate resources and technical skills (each party); (c12) previous performance records on "hard factors," e.g., time, quality, and safety (each party); (c13) compatible organizational culture of involved parties; (c14) interpersonal relations/cultural harmony (individual level); (c15) previous performance records on "soft factors," e.g., joint decision making, joint problem solving, and compromises on unclear issues (each party); (c16) short-listing "capable" (as in items c11 and c12) and "compatible" (as in items c13-c15) potential project partners, instead of "price only" considerations; (c17) disclosing project information to potential partners (as in item c16) at early stages of project for any optional feedback, as appropriate; (c18) seeking specific inputs on constructibility, construction methods, materials, etc. from among potential partners (of item c16), for better project planning; (c19) selecting the best possible "capable and compatible" project team from among potential partners (of item c16); (c20) bringing contractors, major subcontractors, and major suppliers into the project team, in appropriate cases, for longer term interactions to build trust/reliability; (c21) more workshops for better interactions to build trust/reliability; (c22) use of single point responsibility, e.g., only one quantity surveyor (QS) from the contractor representing all contracting parties in the project instead of different QSs for various contracting parties; (c23) group/combined responsibility, as against individual responsibility, e.g., responsibility of binding decision-making on "unclear issues" by a preselected group comprising one person from each major party; (c24) role of an independent full-time facilitator in building trust, teamworking, and "can do" spirit, and enhancing cooperative learning among contracting parties; (c25) role of project manager (PM) as facili- tator as per item c24, given that the PM has the best understanding and control of the project issues; (c26) requirement for an independent full-time facilitator to supplement the PM as per item c24; (c27) company training policy to build adaptable individuals for working with diverse partners (each party); (c28) corporate strategy of building trust with potential partners by doing the "right" things and meeting time and cost targets.

\section{Factors inhibiting building a project-based integrated team for relational contracting (category four)}

The factors inhibiting building a project-based integrated team for RC are as follows: (d01) lack of client's knowledge (about project processes and RC); (d02) lack of commitment from top management of client; (d03) lack of commitment from top management of other parties; (d04) lack of client's initiatives; (d05) bureaucratic client organization; (d06) stringent/incompatible public sector rules and regulations; (d07) public sector accountability concerns; (d08) "price only" selection methods; (d09) commercial pressures on contracting parties; (d10) opportunistic behaviour of one or more contracting parties; (d11) lack of trust/reliability among contracting parties; (d12) unwilling/unenthusiastic participation of contracting parties; (d13) interpersonal/cultural clash (individual level); (d14) incompatible organizational culture (corporate level); (d15) absence of any riskreward plan; (d16) separate/unrelated risk-reward plans for different parties; (d17) exclusion of consultants in riskreward plan; (d18) exclusion of (major) subcontractors in risk-reward plan; (d19) exclusion of (major) suppliers in risk-reward plan; (d20) unfair risk-reward plan; (d21) lack/absence of contractual relations between client and major subcontractors, although they carry out major parts of work; (d22) lack of any relationships/communications between client and major suppliers, although information on and timely supply of some critical materials may improve project planning and works progress; (d23) lack of relationships/communications between consultants and suppliers, although information on source, price, supply time, etc. of some critical materials may improve design, planning, and construction; (d24) lack of relationships/communications between subcontractors and suppliers; (d25) resistance of contracting parties to integrated project culture; (d26) failure to share information among contracting parties; (d27) persistence of "master" (e.g., client/prime consultant) and "slave" concept; (d28) uneven commitment of contracting parties; (d29) discontinuation of open and honest communication; (d30) improper planning, design errors, and omissions; (d31) potential legal liabilities (in resolving noncontractual issues). 
Copyright of Canadian Journal of Civil Engineering is the property of NRC Research Press and its content may not be copied or emailed to multiple sites or posted to a listserv without the copyright holder's express written permission. However, users may print, download, or email articles for individual use. 